improve teaching were to 'improve access' and to 'teach on difficult topics specifically', with teaching preferably delivered online.

Conclusion Teaching materials previously delivered in teaching sessions were recorded and are always now accessible online. A number of other changes were also introduced or are in development; the introduction of a peer-support network amongst trainees, mentorship support for those trainees struggling with exams and congratulatory emails sent to trainees from the Head of School once they'd passed exams.

The biggest development was a new podcast, 'DragonBytes'. Initially aimed to tackle difficult topics identified by trainees, such as metabolic conditions, the podcast now aims to support trainees more holistically with training. Episodes cover a wider range of topics; reflective writing, careers advice, and so on. Since launch, 395 people have listened, and the website has had over 250 unique views. The most popular episode, 'Top Tips for Passing Written Exams' had 88 listens after the first month.

Free open access online medical education (FOAMed) is a growing online trend. DragonBytes has joined this movement by ensuring our material is available to trainees across the UK and advertised to them through social media.

For future work, we aim to evaluate the success of the podcast, and survey our trainees to determine whether these improvements have helped.

\section{G406(P) ACHIEVING CLINICAL EXELLENCE EDUCATIONAL NEWSLETTER}

L Brent, A Soo, S Tran, L Pakkiri. Paediatrics, West Middlesex University Hospital, London, UK

\subsection{6/archdischild-2020-rcpch.349}

Aims Achieving Clinical Excellence (ACE) meetings replaced the traditional morbidity and mortality meetings in a local paediatric department in 2018. This allowed learning to be drawn from positive aspects of care and to develop a SafetyII $^{1}$ approach to patient safety. This project utilised an e-newsletter to disseminate the learning from ACE meetings with supplementary educational content. A secondary goal was to boost staff morale through celebrating excellence in the workplace.

Methods A trainee-led editorial team was established at induction to create content for a celebratory and educational monthly e-newsletter. A free online design and publishing platform was utilised to allow for input from multiple editors and contributors. It was co-ordinated by a senior registrar with supervision from a consultant. The broad sections included:

- Learning from cases - the case-mix ranged from common paediatric presentations to tertiary-level retrieval cases. Content included examples of excellent clinical practice, current guidelines, theoretical knowledge, practical skills refreshers and MRCPCH exam tips.

- Public Health information - featuring a 'Health Promotion Post-it'.

- Self-care and resilience - useful tips to thrive and enjoy work.

- Positivity and team celebrations - compliments were published directly from the 'Gold Star' board, a positivity board where any staff member's everyday achievements can be highlighted. Departmental events and socials were advertised.

Results Over a twelve month period, eleven ACE e-newsletters were created and disseminated across the Trust's two sites. In the latest edition, medical students were supported by the editorial team to have features in the newsletter. Other departments are expressing an interest in producing their own enewsletter. After encouraging informal feedback following each edition, the team are currently collecting more formalised feedback via survey.

Conclusion Empowering trainees to lead on projects like the ACE e-newsletter enables them to educate and inspire others through shared learning. The newsletters have attracted significant praise from other departments within and across the Trust. Trainees are leading their Paediatric department through a cultural change by utilising Appreciate Inquiry techniques (learning by recognising 'the things that go well' rather than solely identifying errors) thereby learning more holistically from patient safety issues or events.

\section{REFERENCES}

1. Hollnagel E., Wears R.L. and Braithwaite J. From Safety-I to Safety-II: A White Paper. [Online] Available at: https://www.england.nhs.uk/signuptosafety/wp-content/uploads/sites/16/2015/10/safety-1-safety-2-whte-papr.pdf

\section{G407(P) A SURVEY OF 'IMPOSTOR PHENOMENA' IN FOUNDATION YEAR 1 DOCTORS}

${ }^{1} \mathrm{~S}$ Warraich, ${ }^{2} \mathrm{E}$ Park, ${ }^{3} \mathrm{D}$ O'Leary. ${ }^{1}$ Paediatric Speciality Registrar and Darzi Fellow, Milton Keynes Hospital, Milton Keynes, UK; ${ }^{2}$ Internal Medicine Trainee, Oxford University Hospitals, Oxford, UK; ${ }^{3}$ (Late) Psychiatry Consultant and Honorary Lecturer at Oxford University, Oxford University Hospitals, Oxford, UK

10.1136/archdischild-2020-rcpch.350

'Help - I'm a fraud get me out of here!'

Background First described in 1978 by Clances and Imes, thoughts of being an 'impostor' at work or university, came to our notice when teaching medical students. Thoughts of being so academically mediocre as to being an impostor often led those more affected students to isolate themselves from informal learning opportunities with peers and from more formal learning supports offered by the university. We became concerned that such thoughts may be more common when students undertake their first year of clinical practice post qualification. Identifying those at risk could lead to offers of greater learning support.

Aims Our primary aim was to ascertain the frequency of impostor phenomena (IP) in newly qualified doctors. A secondary aim was to see whether self-reported changes in self-efficacy (SE) predicted increased risk of impostor phenomena.

Methods All foundation year 1 doctors (2018-2019) were invited to complete the 'Clance Impostor Phenomenon Scale', in addition to baseline data (including age, gender) and a question on changes to self-efficacy since starting the programme. Invitations included an information sheet and respondents could complete the study either online or on paper. Consent to participate was obtained in writing from each respondent. The study was considered to be one of evaluation of service by the hospital's ethics committee.

Results 31 responses, 2 excluded (incomplete). 94\% of the scores showed impostor phenomena.

- $52 \%$ reported moderate to intense impostor phenomena 